\title{
In defense of Forsey's Aesthetics of Design
}

\author{
Monika Favara-Kurkowski \\ University of Warsaw, Poland \\ m.favara@uw.edu.pl
}

Received 31 January 2020; accepted 15 December 2020; published Online First 13 January 2021.

\begin{abstract}
In philosophical aesthetics, discussions on design objects place the notion of Functional Beauty at the fore. Such a philosophical approach can be found in Jane Forsey's book The Aesthetics of Design that focuses on the notion of function to promote the aesthetic value of design and develops an interpretation of Kantian Dependent Beauty around it. Lucía Jiménez Sánchez has recently put forward several flaws of Functional Beauty accounts. She presented several practical cases as evidence for the narrowness of Functional Beauty accounts. Two cases are presented against Jane Forsey's theory of Dependent Beauty, holding that it excludes other properties from appreciation that are not necessarily related to functionality, i.e., expressive properties. The purpose of this article is to show that these criticisms leveled at Jane Forsey's proposal for an aesthetic theory of design are unfounded and are based on a misunderstanding of the structure of judgments of beauty in her system. Despite this, these criticisms highlight the need to clarify the purpose of the aesthetics of design.
\end{abstract}

Keywords: design; aesthetics; function; beauty; aesthetic appreciation

\section{A contemporary theory of design aesthetics}

In the last decade, philosophical aesthetics has turned to design (Forsey, 2013; Folkmann, 2013; Parsons, 2016 et al.) since it seems to challenge the paradigms imposed by the philosophy of art. The novelty of these approaches lies in the appreciation of design, not through the prism of art criticism, but qua design. First of all, the central assumption of research is that design has an important aesthetic dimension, destabilizing the privileged position that fine art has occupied in philosophical aesthetics. Secondly, this aesthetic dimension cannot be reduced to a mere aestheticizing factor, making everyday objects lose their functional role (ref. Baudrillard, 1996), making them fall back into the oblivion of philosophical aesthetics. Consequently, these accounts claim that making a philosophical case for design cannot be grounded on formalism alone. It must also include the notion of function. 
In this paper, the focus is on Jane Forsey's The Aesthetics of Design as the theory that has been able, with great insight, to define what is specifically aesthetic in design, to make it a valid candidate for philosophical research. The Canadian philosopher tries to localize the aesthetic in the discussion on design specifically, and her concerns arise in dialogue with philosophers of Everyday Aesthetics. This theoretical paradigm of philosophical studies draws attention to the aesthetic dimension of everyday life, which, according to its exponents, has been underevaluated by art-center aesthetics. Nevertheless, as part of this debate, Forsey highlights two fundamental problems of this paradigm.

First, there is an "ontological confusion," which deserves a categorization exercise. For this reason, Forsey proposes to limit the area of investigation to design as a privileged subject to reveal the salient aesthetic aspects of everyday life, in contrast to that of art and nature. She defends the view that ,we can best begin with an aesthetics of the everyday if we focus on design." (Forsey, 2013, p. 236) Second, in the literature so far, the boundary between what is aesthetic often fades into what is ethical, avoiding an autonomous theory of aesthetics for the everyday. She claims, „[w] hat many of these thinkers also have in common is a desire to link our aesthetic experiences of the everyday with moral experiences and judgements or with ethics in some broad construal of the term." (Forsey, 2013, p. 201) To overcome these problems, Forsey expands the applicability of the judgment of beauty to functional objects. For this purpose, she reaches to the Kantian theory of "Dependent Beauty" (pulchritudo adhearens) since she endorses the view that the aesthetic "constitutes a mental act rather than a property of objects [...] or a form of physical pleasure." (Forsey, 2013, p. 73) This notion allows Forsey to describe how the recognition of purpose (functionality) influences the assessment of the aesthetic dimension of design. To be specific, she proposes an aesthetics of design based on evaluating an object „because of the perfection in the way it fulfills its purpose.” (Forsey, 2013, p. 162) However, in the final instance, it should be noted that this statement is also valid for handcrafted objects, which is why the Canadian philosopher hastens to specify that:

[...] the free play of the faculties when faced with a work of craft will consider the contingency of the way that object fulfills its function by means of the individual skill at creating it from a given raw material. With judgements of design, we do not attend to this aspect of the object: we feel no individual hand at work when we appraise a laptop computer or a car, and we do not judge it according to how a single individual has manipulated some raw material to produce it. (Forsey, 2013, p. 180)

Moreover, for design objects, where the concept is closely linked to their function than in other cases, Forsey proposes that „our appraisal of [design objects] will be tied to this intended function rather than to whatever uses they might serve." (Forsey, 2013, p. 43) To establish whether the object perfectly fulfills its function, we must know its intended use; in other words, we could not judge a design object as beautiful in a dependent sense if we do not know what this object is used for. In most cases, this knowledge is of cultural derivation where form and function are mediated by words-e.g., "chair," "kettle," "gun"-and, Forsey adds, that the function - the concept of "chair," "kettle," "gun"- depends on what a designer intended an object to be, to further avoid confusion with the notion of "use." She repeatedly underscores this point: 
[...] while a tire may function as - or be used as - a swing, its function is not to be a swing, and if we define it by its function, we call it a tire, not a swing. (Forsey, 2013, p. 30)

The specific structure of these judgements is not founded on an ontology of design constituted of sufficient and necessary conditions, since ,this approach is too constrictive," (Forsey, 2013, p. 14), and it would run aground on counter-examples. Instead, Forsey singles out a class of objects that qualify for philosophical attention, and that is distinct from art, craft, and nature, established by the way „we commonly speak of design” (Forsey, 2013, p. 21, italics mine). The four "intuitive characteristics" Forsey derives are functionality, immanence, muteness, and mass-presence. To be more specific, objects have to satisfy a practical purpose to be considered objects of use; therefore, they are functional. Furthermore, we don't expect a design object to ,achieve the transcendence of art” (Forsey, 2013, p. 28). In other words, since design objects pertain mainly to quotidian life, they are not directly subject to metaphysical problems; therefore, they are immanent. This aspect links to their lack of expressive content, in the sense that the designer, unlike the artist, does not want to communicate anything profound, or at least we do not expect her/him to do so, i.e., they are mute.

Furthermore, a design object is characterized by the fact that it is mass-produced by technological means, rather than hand made. Forsey is not specifically interested in hybridization cases between art and design as, instead, happens for the categories of DesignArt and ArtDesign. Alex Coles claims that the former is ,the type of art that you can look at while you are sitting on it" (Coles, 2005, p. 8). DesignArt refers primarily to art that reproduces the practices of design, as, for example, planning aimed at some practical use. Paradigmatic is the case of Tobias Rehberger's cafeteria at the Palazzo delle Esposizioni della Biennale in Venice (2009). This functional space, open and in service to the Biennale guests, was a functional work of art. Designed as a restoration point, it aimed at overcoming the pure self-reference of the work of art, through unusual intertwining between imagination and functionality that open up to dialogue with the public. (Di Stefano, 2016) Instead, ArtDesign refers to the practice of design, which emphasizes the conceptual value of the product over its functionality, or uses strategies pertaining both to art or craft, like site specificity (mostly museums) or limited editions. In both cases, we are dealing with objects that arise from an expressive necessity, where both the artist and the designer intend to express an individual conceptual reflection.

As Forsey intends it in critically appraising design in our daily life, the designer's role and expressiveness are marginal. She writes:

With design, we merely judge the relative perfection of the thing in fulfilling its function, absent any knowledge of — or often any interest in—who actually did the work. (Forsey, 2013, p. 180)

The desire to divorce design from what the philosophy of art, art theory, and criticism has so far formulated for the work of art, therefore divorcing it from artistic expressiveness and creative manual skills, has the specific purpose of appealing to the peculiar aesthetic perspective that design bears, in order to shed light on the everyday. 
Forsey's theory of design is a more complex philosophical endeavor than a mere argument in favor of acknowledging design by philosophical aesthetics. There is no doubt that design is a valid subject of aesthetic appraisal, but Forsey wants to define how this appraisal is specifically aesthetic for design, without falling into the trap of mere aestheticization. The decision to take the tortuous road of Kant's Third Critique, often difficult to grasp for non-specialists, also reveals the deep foundation of her theory: first, the rejection of an essentialist definition of what is properly aesthetic; and, second, the „defense of the aesthetic as an autonomous and significant facet of human experience" (Forsey, 2013, p. 243).

\section{Criticism of Functional Beauty and Replies}

Lucía Jiménez Sánchez (2019) has addressed some limits of Functional Beauty accounts about design in particular. To make her case, she presents several practical cases as evidence for the narrowness of Functional Beauty accounts. In this paper, I will focus on what Jiménez Sánchez terms as „the problem of exclusivity” and what I have termed „the problem of impractical objects" and ,the problem of a single function," which are both problems related to the emphasis placed on the notion of function.

I argue that these criticisms directed toward Forsey's theory are ill addressed. These criticisms are unfounded based on a misunderstanding of the structure of beauty judgments in Forsey's system.

Despite this, these criticisms highlight the need to clarify the purpose of the aesthetics of design.

\subsection{The problem of impractical objects}

One criticism that Jiménez Sánchez addresses to functional accounts is the abuse of the notion of function in the appraisal of design. Such abuse puts those design objects that „fail to accomplish [the] proper function as presumably practical" (Jiménez Sánchez, 2019, p. 144) in the background.

Having clarified what Forsey means by design objects, this "limit" of her definition is evident. If an object is not practical, we will most likely not consider it an excellent example of an object of its kind, let's say a comfortable chair. However, Jiménez Sánchez adds something more. She wants to emphasize that the practice of design does not focus solely and exclusively on the production of practically functional objects. Instead, as has already happened with art, designers have begun to reflect on their practice and the postulates of design theory, expanding their sphere of action toward more conceptual work. In this regard, Jiménez Sánchez presents the "chair" of Katerina Kamprani Uncomfortable Chair 3. This chair is part of a collection of deliberately uncomfortable everyday objects that make simple daily tasks, e.g., sitting, a real challenge. Kamprani's work is purely conceptual, not only because it remains mostly as a rendering or prototype, but because, according to the designer herself, by sabotaging the user experience, she intends to convey a message: „Comfort is better conceived when absent” and 
"function is the most important thing" in design (Kamprani, 2018). She ironically contemplates the chair qua chair's notion, she plays with the standard features that make a chair a chair, but her final product is not a chair. However, if we want to insist that it is a chair, we have to consider that it is uncomfortable, and as such, we will not positively evalu-ate it as a good specimen of a chair-a perfect chair.

Jiménez Sánchez is right in pointing out that designers are more and more following the path of avant-garde endeavor, but is wrong in insisting that ,[b]eautifully said, [...] functional accounts are not consistent with design cases in which aesthetic judgments are not entirely supported by the object's practical or functional success.” (Jiménez Sánchez, 2019, p. 144)

I want to argue that appealing to Kant's theory of beauty does not exclude the appreciation of impractical objects. Before Forsey cast out Dependent Beauty specifically for design objects, this notion was already applied to non-practically functional objects. As Robert Stecker points out, „Kant suggests that a proper understanding of the appreciation of most art is not captured by the notion of a pure judgment of taste" (Stecker, 1987, p. 89) but impure ones, the object of which is always Dependent Beauty. What Forsey shows is how the function specifically affects this impure aesthetic judgment, not that only function affects it. For example, we could defend our aesthetic appraisal of Uncomfortable Chair 3 by pointing to its formal features alone. This justification would make us even more faithful to the original Kantian theory.

What Jiménez Sánchez has to do is cast an argument or a definition that supports the fact that Kamprani's practice results in objects commonly understood as design objects and not, let us say, sculptures or a physical manifestation of a critique of design theory. Suppose we want to develop an aesthetic theory for design seriously. In that case, firstly, one has to justify what is particularly aesthetic for design that has not already been cast out for other aesthetic objects. The risk of not doing this is to consider design as a secondary art form precisely because it submits to other creative practices.

\subsection{The problem of a single function}

Most of the cases presented in support of Functional Beauty accounts refer to objects with a single function, i.e., simple objects such as kettles or shoes. Jiménez Sánchez argues that if we apply these theories to more functionally complex objects, we cannot make a judgment of beauty. She claims that ,[t]his problem revolves on the idea that design objects are identified by a single functional purpose.” (Jiménez Sánchez, 2019, p. 144)

In this regard, Jiménez Sánchez presents This is a Lamp, by Tobias Wong, another designer who took the initiative in the nebulous area around the world of traditional design. Among other "para-design" objects he created, this specific object is an adaptation of Philippe Starck Bubble Club chair - a plastic outdoor piece of furniture - into a „lamp” by inserting a lighting system inside it. According to Jiménez Sánchez, this product „,introduces that not only proper function is responsible of design beauty but accidental functions too" (Jiménez Sánchez, 2019, p. 144). 
Unlike Glenn Parson and Allen Carlson, Jane Forsey defines the proper function of the object, not as an essential property of the object, but as established by the designer (intended function). In other words, making a correct aesthetic judgment implies that we understand what function the designer intended the object to perform. This definition of function ,may well sport functional innovations too," (Forsey, 2013, p. 58) of which This is a Lamp is an example. Moreover, the intended function and the function we apprehend are not an essential property of the object. It is a problem of semantics if we wish, a ,consideration of our linguistic practices.” (Forsey, 2013, p. 15) It might be that in the distant future, the "lighting chair" will become a typical kind of object in our homes, and other designers, in addition to Tobias Wong, will improve this kind of object, as a compound of the concept of sitting and of giving light, among which we can compare and assess our judgment.

The first time we see a lamp with the shape of a chair, according to the Kantian theory of beauty, refined by Forsey, we can critically appraise the object as a Free Beauty specimen. This is because we don't have a definite concept at this time in history. Alternatively, we can appraise it as Dependent Beautiful for its sitting function and individually for its lighting function. Associating a chair shape with light is a creative (and critical) act on the designer's part, which Forsey does not develop in detail. ${ }^{1}$ What Forsey intends is that if any given time in history, we have never experienced a lamp with the "non-standard" lamp shape at that time, we can make a pure judgment of beauty. ${ }^{2}$ However, from now on, as we have experienced it (perhaps even used it), we have a concept for this type of object. Forsey does not deny that „the binomial model form-function is problematic” (Jiménez Sánchez, 2019, p. 146); indeed, her theory emphasizes the fact that an object can „fulfill its function in a variety of ways, [and] these ways themselves should also be part of our overall appraisal of it." (Forsey, 2013, p. 164). It is precisely by acknowledging this fact that Forsey's theory allows taking into consideration not only the localized, specific, and personal interactions of who is formulating the judgment (Forsey, 2013, p. 216) but also the historical evolution of objects of design. The cases presented by Jiménez Sánchez are not born from a void, but are formal and functional evolutions of pre-existing objects.

\subsection{The problem of exclusivity}

Both the previous cases are introductory to the more pressing problem Jiménez Sánchez sees in Functional Beauty accounts: the problem of exclusivity. She claims that ,[t] $]$ he Functional Beauty Account is wrong in thinking that aesthetic judgements which are partly based on functional considerations are to be exclusively based on those kinds of considerations" (Jiménez Sánchez, 2019, p. 146). In other words, these accounts exclude from appreciation other properties that are not necessarily related to functionality, i.e., expressive properties. As we have seen, Forsey seems to endorse precisely this aspect of design when she claims that design objects are mute. Nevertheless, this claim is bound to a working definition that Forsey casts to

\footnotetext{
${ }^{1}$ For a better treatment on the role of creativity and imagination in design practice, see: Folkmann, 2013.

${ }^{2}$ Which in fact are very rare.
} 
intuitively discern design objects from works of art, nature, and craft objects to find what is specifically aesthetic in our judgment directed to design objects.

Moreover, Forsey does not define design in terms of its necessary and sufficient conditions, as we have seen. On the contrary, she bases her definition on ,intuitions” on design reflected „in the phenomenology of our concepts and our linguistic and creative practices," (Forsey, 2013, p. 11) positioning her ontology between a strict metaphysics of objects and an analysis of language and concepts. „Muteness” is a descriptive criterion, not an essential property of design objects.

We cannot forget that one of the main tasks of Forsey's project is arguing for the inclusion of design in the scope of philosophical aesthetics, thus developing a ,picture of what makes design unique, and aesthetically interesting" (Forsey, 2013, p. 15). This strategy, far from belittling design, avoids considering the aesthetic experience of design according to the modes of artification and everyday life's aestheticization. Forsey does not suggests that claims that „design cannot be creative or spontaneous but that it cannot be only this." (Forsey, 2013, p. 59)

The definition that Sanchez has in mind for design beauty is too broad, as to have insufficient explanatory power. This does not mean that actual design practice does not (or should not) expand in other fields, but because we have an intuitive understanding of what design is with respect to other practices, we can say that it expands in them. In other words, Forsey does not exclude that design practice is much more artistic than a Bic Ball-pen or an anonymous kettle might reveal. Nevertheless, for the appreciation of an object as a good specimen of its kind (pen or kettle), the designer's expressiveness is not as fundamental as its function.

Nevertheless, Jiménez Sánchez is not entirely astray. Focusing on the debate with Everyday Aestheticians, Forsey leaves out much of the research design theory has carried out, making her theory more a challenge for philosophical aesthetics than for design studies (Margolin, 2015). Furthermore, using the classification provided by Folkmann, we may say that Forsey focuses mainly on "anonymous" design objects, which are objects that „lack a surplus in appearance” and, therefore ,affirm existing status quo" (Folkmann, 2013, p. 64). But this is an apparent problem relating to how, at the beginning of her book, Forsey distinguishes design from other subjects on which aesthetics has focused. By deepening her aesthetic theory, and more specifically, her interpretation of the Kantian notion of Dependent Beauty, regardless of how complex it may be, these criticisms turn out to be unfounded.

The problem of exclusivity, at least in Forsey's account, does not exist, or if it does, is more „the virtue of exclusivity," that is, design objects are the best candidate to justify the understanding of aesthetics not merely as a philosophy of art. „I am seeking here to distinguish design as a set of practices and objects from other categories common to aesthetic theorynotably art and craft - because the particular characteristics of design [...] merit separate treatment, especially in our approach to their aesthetic evaluation" (Forsey, 2013, p. 14). If we need a theory of expressiveness, the philosophy of art has plenty.

The beauty that is particular to design (and craft) is Dependent Beauty as we appraise the object because of the perfection in the way it fulfills its purpose, but it is not the only genus of beauty that we can apply to design. Forsey discusses similar cases like those presented by Jiménez Sánchez. These are cases where the designer comments on the nature of design itself. 
Forsey claims that ,we can pick out a few such examples [which] indicates that we see these as stand-out exceptions to the majority of designed objects: we do not generally approach our toothbrushes or coffee-pots or hammers as having a content that is the result of the singular vision of their designers." (Forsey, 2013, p. 66)

Focusing on expressiveness, which Forsey individuates as one of the main concerns of artcentered aesthetics, would proclaim "our response to fine arts as the form all aesthetic experience should take" (Forsey, 2013, p. 195), trivializing, at the same time, what is unique about design.

\section{Conclusion}

By apparently denying the possibility of counting design as art, Jane Forsey's proposal might awaken concerns in the eyes of designers, design critics and theorists. The concerns arise because Forsey gives a definition of design that is specifically formulated to distinguish it from art, but also from nature and craftsmanship - three categories to which aesthetics has long been committed.

Design is a very complex practice with its own history, intertwined with that of the fine arts, but has also always been able to keep its distance by developing its own theory, often methodologically too close to technology studies or science. Jiménez Sánchez wants to draw attention precisely to this fact. The practice of design cannot be reduced to purely functionalist considerations, especially by aesthetics, which, as a theoretical perspective, has accumulated substantial interpretative expertise of human creative work. This expertise should also be applied to design objects, which are communicative, emotional and are the results of designers" creative work. Therefore, criticisms that address Jane Forsey's characterization of muteness of design objects are understandable. Nevertheless, we must remember that ,an ontology of design simply seeks to describe the phenomenon; how we evaluate it is another matter" (Forsey, 2013, p. 18).

The novelty that Forsey presents is not to be found in her working definition of design but in her interpretation of the Kantian theory of taste and the elaboration of the concept of beauty so that it does not reduce design to mere beautification. This way, Forsey remains critically engaged with the tradition of philosophical aesthetics, and argues that „design can be defined and evaluated in ways that are not wholly unlike the other, more familiar aesthetic subjects" (Forsey, 2013, p. 4). At the same time, she shows the uniqueness of the structure of aesthetic judgment of our experience of design, ,in an admittedly very complex way” (Forsey, 2013, p. 128). ${ }^{3}$

By localizing the aesthetic in a mental act, by considering beauty as a particular intellectual pleasure, and by pointing out that aesthetic judgments do not occur in a conceptual void, Forsey's theory seems immune to the presentation of counter-examples. In other words, to present a critique of the theory of Dependent Beauty, it is not enough to present counter-examples that attempt to undermine the working definition of design presented by Forsey. At the

\footnotetext{
${ }^{3}$ Forsey refers to Kant's theory, but the same comment can be made to her own theory.
} 
same time, we cannot negate that it is somehow reductive - it does not encompass all the nuances of the practice of (contemporary) design by focusing on a familiar and intuitive understanding of design as we encounter it in our daily lives.

Nevertheless, if we want to defend design as somehow with a higher status, as art, we must also deal with the fact that, paradoxically, we reduce its field of action. Forsey justly remarks that ,[d]esign is more complex [than art] in that it is not always or only an aesthetic object, and our responses to design are, rightly, more varied because of the many different ways design intersects with our lives" (Forsey: 2013, p. 18). Her theory of aesthetic judgment considers precisely this. It is the beauty in the consumer's eyes, an awareness that does not make the object disappear in its use, consumed by its function, but enhances it as an object with its specific aesthetic.

In conclusion, this leads to the most pressing question: what do we want to achieve with an aesthetic theory of design? If art has been the privileged subject of aesthetics, particularly so when the avant-garde managed to put it in crisis, what does design offer that art has not already? The answer is simple, almost banal, and Forsey, while not asserting it directly, makes it emerge throughout her book. Art has always been in tension with life. The relationships that bind art and life have been the subject of much reflection of art and its philosophy. Some of the most fundamental theories of aesthetics are linked precisely to this relationship. Just think of John Dewey's aesthetics and the Brillo boxes created by Andy Warhol, which led Arthur Danto to theorize the indiscernibility between artistic product and ordinary objects, the world of art and everyday life. On its part, design has always been part of everyday life; design is what makes everyday life what it is. An aesthetic theory of design has a privileged position in this matter than the philosophy of art has. This „offers an avenue both for broadening the scope of aesthetic inquiry and for re-integrating aesthetic theory into philosophy as a whole" (Forsey, 2013, p. 3).

Therefore, when Jiménez Sánchez claims:

design objects do not have to be quotidian to be design. There are lots of design objects that are not part of our daily lives, but that are still designed, such as particles accelerators or conceptual design cases. (Jiménez Sánchez, 2019, pp. 4-5)

she expresses a narrow understanding of the importance of the everyday for aesthetics. A particle accelerator $i$ an everyday object for CERN physicists, and a conceptual design is an everyday object for those who designed it. This should suffice to make us understand why an aesthetic theory of design does not need to mimic the path of the philosophy of art and art criticism.

\section{References}

Baudrillard, J. (1996). The system of objects. London New York: Verso.

Coles, A. (2005). DesignArt. On art's romance with design. London: Tate Publishing.

Di Stefano, E. (2016). DesignArt. Ibridazioni creative tra arte e oggetti d'uso. Rivista di estetica, $61,65-76$. 
Folkmann, M. (2013). The aesthetics of imagination in design. Cambridge, MA: MIT Press.

Forsey, J. (2013). The Aesthetics of Design, Oxford University Press.

Jiménez Sánchez, L. (2019). Understanding Design Aesthetics beyond Functional Beauty Accounts. Laocoonte. Revista de Estética y Teoría de las Artes, 6, 137-149.

Kamprani, K. (2018). Do we really have to?. TEDx talk for TEDxPoznan [https://youtu.be/aMKrZMbfaTg]

Margolin, V. (2015). Reviewed Work(s): The Aesthetics of Design by Jane Forsey. The Review of Metaphysics, 68(3), 657-658.

Parsons, G. (2016). The philosophy of design. Cambridge, UK: Polity Press.

Stecker, R. (1987). Free Beauty, Dependent Beauty, and Art. The Journal of Aesthetic Education. 21(1), 89-99.

Monika Favara-Kurkowski is a PhD-candidate in Philosophy at the Doctoral Schools of Humanities at the University of Warsaw, Poland. She is a designer, as well as a philosopher. Her interests focus on the aesthetic aspects of the design process and its products, but primarily on the aesthetic experiences related to everyday life. 